\title{
THROMBO-EMBOLIC PRIMARY PULMONARY ARTERIOSCLEROSIS
}

\author{
BY \\ P. J. BARNARD \\ From the Institute for Pathology, University of Pretoria \\ Received September 3, 1953
}

That diverse factors are concerned in causing arterial pathological changes largely confined to lungs is clear from a review published by McKeown (1952). Only one of these factors, incorporation of fibrin into arterial intima, is here considered as a cause of pulmonary arteriosclerosis and cor pulmonale.

Goedel (1930), Belt (1939), and according to Duguid (1946) Rokitansky were all aware that incorporation of blood clot into vascular intima produced lesions simulating arteriosclerosis. Duguid once more directed attention to this fact and following his lead, various workers undertook experiments to test his conclusions which were based on human autopsy material By injecting fibrin emboli intravenously into rabbits it has been shown that lesions like arteriosclerosis may be induced in small branches of the pulmonary artery (Harrison, 1948 and 1951; Muirhead and Montgomery, 1951; and Barnard, 1953). These workers used emboli prepared in vitro either from the animal's own blood or from blood of a different animal.

Assuming that experimental thrombo-embolic arteriosclerosis has significance for man, primary pulmonary arteriosclerosis might be a disorder of the blood characterized by repeated and protracted pulmonary embolism by showers of minute clots originating in systemic veins, where conditions are favourable for intravascular coagulation. If such emboli formed in systemic venous blood, few would escape the pulmonary arteriolar and capillary filter and thus significant arteriosclerosis would be confined to the lungs.

Embolic experiments that aimed at discovering the role blood clot plays in causing pulmonary arteriosclerosis would, however, have added significance if lesions were also brought about by injecting substances that would precipitate fibrin in circulating blood. Heard (1952) injected magnesium adenosine triphosphate together with Russell viper venom and studied arterial lesions so caused. McLetchie (1952) conducted similar experiments using Russell viper venom and thromboplastin extract. Others have recorded fibrin embolism of pulmonary vessels using thromboplastin extract or highly diluted thrombin solution, but their object was the study of blood coagulation and not the arterial changes (Jürgens and Studer, 1948; Ratnoff and Conley, 1951; Page et al., 1951; and Schneider, 1951). Schneider has shown, moreover, that placental trauma to rabbits caused fibrin embolism severe enough to kill, and that in human abruptio placentæ placental thromboplastin may enter the maternal circulation so causing fibrin embolism of the lungs, in some cases leading to death.

This paper describes pathological changes in mouse and rabbit lungs due to thromboplastin extract injected intravenously: extract was not mixed with an unphysiological coagulant as in previous experiments of this kind. It also argues that protracted embolism by minute clots is one cause of primary pulmonary arteriosclersois and cor pulmonale in man.

\section{MATERIALS AND Methods}

Twenty young adult rabbits of either sex and various colours, and 140 white mice of either sex and of the strain maintained in this institute, were used: 18 normal mice and 6 normal rabbits served as controls. 
Mice. All mice were injected with thromboplastin extracted from difco desiccated rabbit brain; to extract thromboplastin, this was mixed with normal saline and incubated in a water bath at a temperature of $47^{\circ} \mathrm{C}$. The mixture was agitated briefly at 3-minute intervals, and after incubating for 10 minutes the extract was filtered through a pledget of cotton wool. The extract so made was then diluted further with normal saline and by trial on mice the concentration was adjusted so that a lethal dose was less than $0.2 \mathrm{ml}$. This was done to avoid killing animals by excessive increase of blood volume. As extracts prepared on different days from the same batch of desiccated rabbit brain were found to vary in strength when tested on the living animal, actual doses administered have not been stated here. Mice were injected into their tail veins.

In the first series, 28 mice that were given one lethal dose each died from fibrin embolism of the lungs. In the second series 112 mice received 2 to 12 injections in experiments lasting from 1 to 44 days. These mice were generally injected at 3- to 4-day intervals, though on a few occasions a week elapsed between. On each injection day a small initial dose was used, the dose being increased by small amounts for each successive mouse injected until one was killed by thromboplastin extract. Mice were injected at random. Others then received an amount slightly less than the fatal dose. Even so, occasional animals died from a dose that was not lethal to their fellows. This ensured that animals received high sublethal doses. Any mouse in which injection failed was killed. In 23 of this group organizing emboli were discovered in lung arteries.

Rabbits. All were injected with brain extract prepared from animals of the same stock as those used in this experiment. Thromboplastin extract was prepared in the same way as for the mice. Rabbits received repeated injections on a plan similar to that used for mice. Injections were generally given bi-weekly but on several occasions, as in mice, once a week. They received from 2 to 21 injections in experiments lasting from 7 to 93 days. Injections both in mice and rabbits were given rapidly.

The Preparation of Lung Sections in Mice and Rabbits. Asceptic precautions were observed in giving injections. This also applied to preparation of thromboplastin extract, though this substance, for obvious reasons, cannot itself be sterilized. Each animal was dissected immediately after death, and the lungs fixed in 4 per cent neutral formaldehyde solution. All lungs were distended with the solution during fixing to permit easier interpretation of changes in alveolar walls. In mice, heart and lungs were embedded in one piece, the microtome knife being carried through the whole coronally to include both lungs and both ventricles in the same section. In rabbits each of the lower lobes was divided into three portions. Other lobes were embedded whole. All sections were stained with hæmatoxylin and eosin and Weigert's elastic tissue stain counterstained with van Gieson. Frozen sections were also made of the lungs and stained for fat with Sudan III.

\section{Pulmonary Lesions}

Mice. Numerous unorganized fibrin masses were found in lung vessels and often in the right ventricle also in all but 5 mice dying immediately after an injection. In these 5 death was ascribed to anaphylaxis. Fibrin was not found in the left ventricle in a single mouse.

In only 23 mice out of the 112 in the second series were organizing emboli found: only 4 mice showed late stages of fibrin organization. Fig. 1 illustrates occlusion of the arterial lumen by fibrin which is beginning to recanalize. As there were not more than two organizing fibrin lesions in each of these 23 mice the total number of lesions was too small to permit special description. No lesion representing the healed stage of fibrin embolism was encountered. Otherwise, lesions elicited in mouse lung by fibrin masses corresponded in a general way with those which will be described more fully for rabbits.

Rabbits. Of the 20 rabbits, 18 died directly after injection and 2 were killed by air embolism to terminate the experiment. The 18 all showed extensive pulmonary embolism by unorganized fibrin and often also masses of fibrin within the right ventricle. Emboli were present in many vessels in all lobes of the lung, either loose or adherent to intima, but mostly impacted in small muscular arteries and capillaries. Only occasionally was fibrin found in pulmonary veins. In large arteries fibrin threads composing emboli tended to an oblique or longitudinal arrangement (Fig. 2), an arrangement not clearly recognizable in smaller muscular arteries and capillaries. Fibrin emboli always contained entangled erythrocytes and leucocytes, but the fibrin component invariably predominated. 


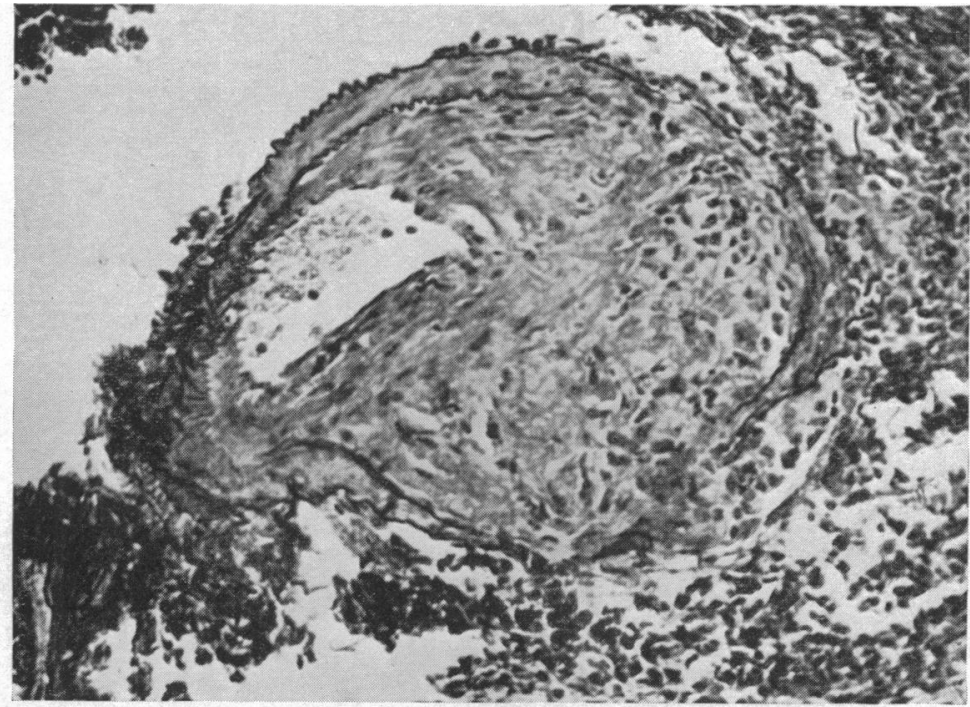

Fig. 1.-An organizing mass of fibrin undergoing recanalization in a small muscular artery. In lower right corner, media and both elastic laminæ are destroyed and replaced by fibroblasts admixed with round cells which extend into the adventitia (Weigert-van Gieson, $\times 240$ ).

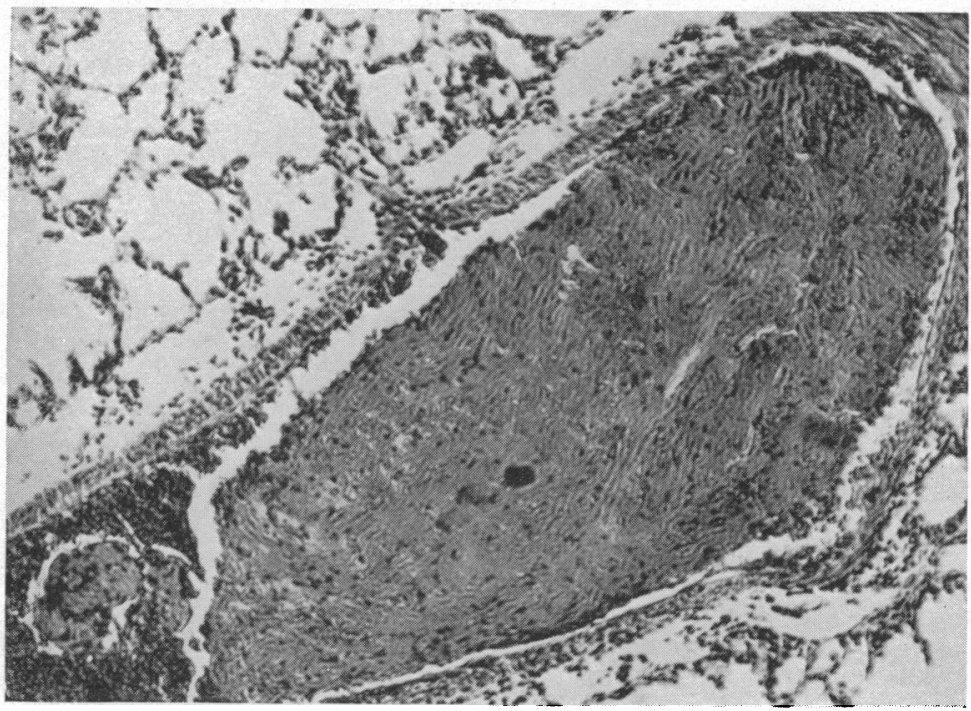

FIG. 2.-Sections of an artery stretched tangentially and obstructed by a fibrin mass showing oblique fibrillar arrangement (Hæmatoxylin-eosin, $\times 70$ ).

As in mice, organizing emboli were scanty. Numerous sections from the lungs of each animal were necessary to discover lesions sufficient for description. Moreover, in three rabbits no organizing lesions at all were found. Both scantiness of lesions or their complete absence was presumed to be due either to failure of intravenous coagulation following injection of thromboplastin extract or to lysis of any clots which had formed.

Because rabbits and mice received multiple injections, an attempt to establish the time taken for individual features of lesions to appear or how long they lasted, was not thought to be possible.

Swelling, separation, and proliferation of endothelial cells were present at and remote from 
sites of embolic impaction. At embolic sites fibrin became enveloped by endothelium, sometimes several layers thick: endothelial cells also invaded emboli.

Cellular Infiltration of Vessel Walls. In lesions thought to be recent, neutrophils adhered to endothelium over long stretches and infiltrated vessel walls mainly from the lumen. Other lesions, apparently older, were pleomorphic due to the addition of lymphocytes, mononuclears, plasma cells, and eosinophils. In small arteries, cellular exudate sometimes obscured segments of the vessel wall, especially in mice. Fibrinoid necrosis of vessel walls was nowhere encountered: nor was there aneurysmal dilatation or hæmorrhage. Fig. 3 shows an unusually pronounced example of thromboplastin extract induced arteritis. In more quiescent lesions, cells with the characteristics of fibroblasts were recognizable in organizing masses of fibrin and in intima underlying these lesions. In a few arteries, fibroblasts were recognizable in media and adventitia also.

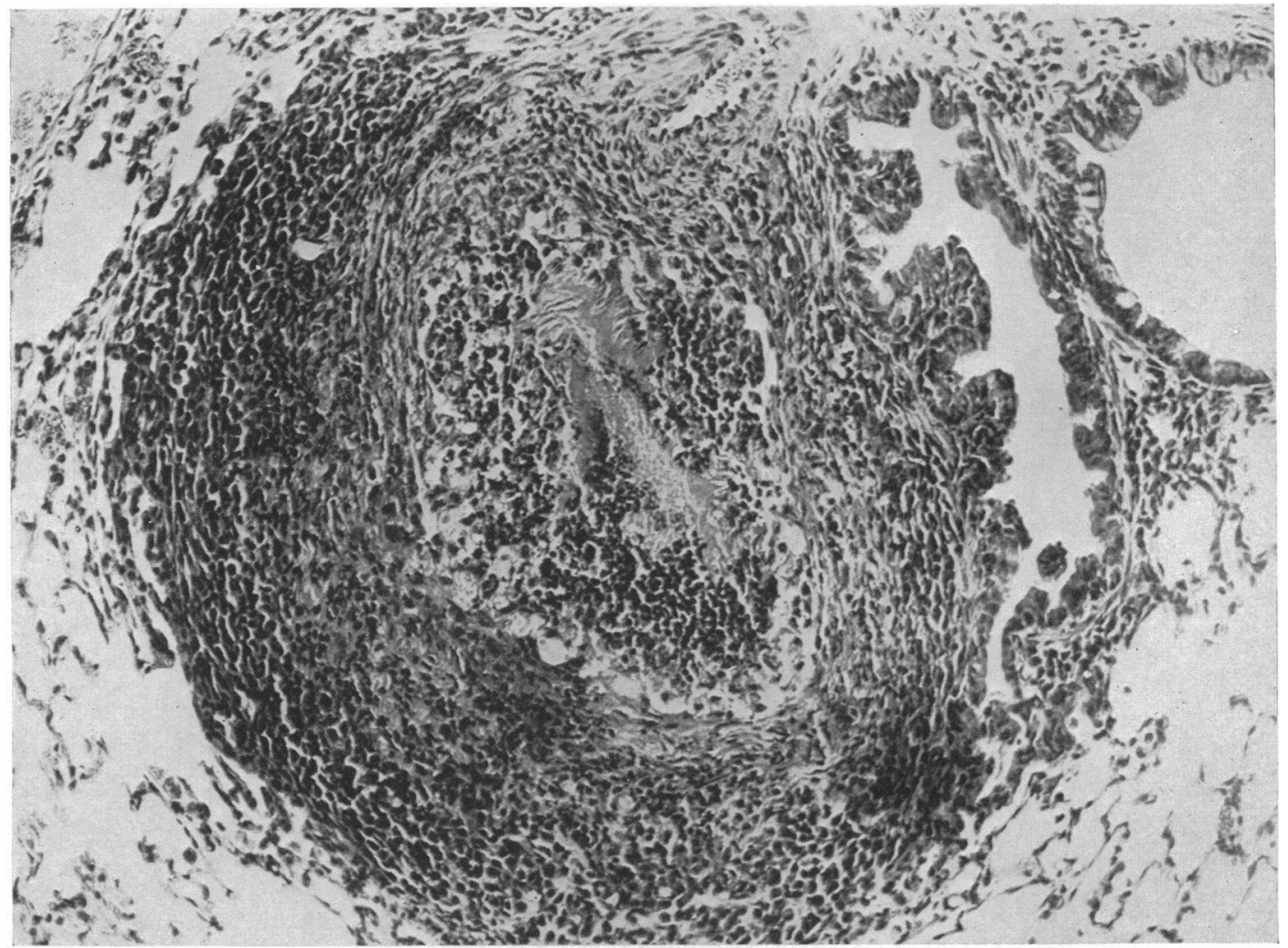

FIG. 3.- "Fibrin arteritis" in its most pronounced form. Arterial wall almost completely obscured and destroyed by subacute inflammation. Shreds of fibrin are still recognizable at the centre: no fibrinoid change (Hæmatoxylin-eosin, $\times 165$ ).

Arterial Elastic Tissue. In minute muscular arteries emboli sometimes stretched the internal elastic lamina to extreme thinness, though without rupture. At sites of organizing emboli damage to this membrane was evident in various ways, most commonly as rupture (Fig. 4) but also as thickening, splitting, and reduplication. Away from lesions, arterial elastic tissue was not involved.

Fate of Fibrin itself. Envelopment and invasion of fibrin masses by endothelial cells, neutrophils, and other inflammatory cells, has already been mentioned. In more quiescent lesions, cells within emboli thought to be endothelial in origin were seen to have developed branching cytoplasmic processes like those of fibroblasts. The end stage of fibrin organization was a collagenous mass sometimes containing new elastic fibres applied eccentrically to the vessel wall (Fig. 5 and 6): 


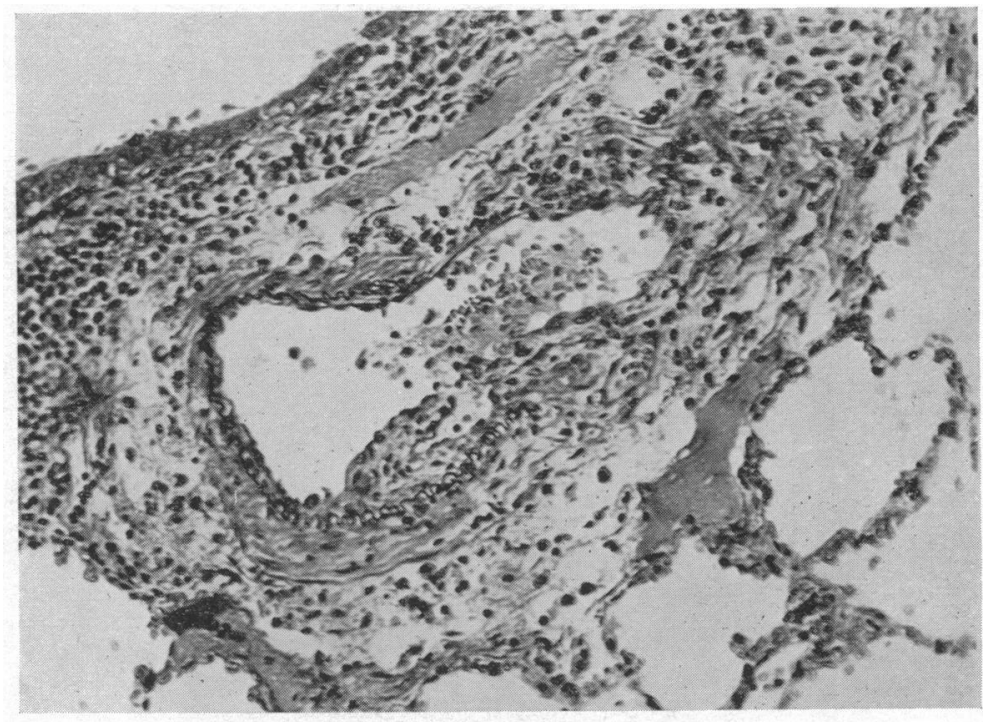

FIG. 4.- Segmental replacement of arterial wall by granulation tissue: periarterial cedema and subacute inflammatory cell infiltration (Weigert-van Gieson, $\times$ 200).

such lesions were scanty. Rarely, œdematous polypoid lesions or œdematous connective tissue intimal plaques in which fibrin could not be recognized, were seen. Organizing fibrin sometimes lost its eosinophilia and took on basophilic staining qualities.

Arterial Media. Medial damage was encountered only in immediate relation to arterial lesions. A few arteries showed inflammatory destruction of their walls (Fig. 3 and 4) and some others medial scars sometimes containing distorted elastic fibrils.

Edema, usually adventitial, was infrequently noted (Fig. 4). Though most pronounced in immediate proximity to lesions, it was also found away from emboli, sometimes as a curious lesion limited to the intima. In the adventitia, œdema took the form of a broad mantle containing inflammatory cells. No increase in adventitial collagen was encountered in any lesion.

Fat. Frozen sections of recent embolic lesions showed inconstant dusting of fine fat globules within fibrin masses, presumably derived from included plasma lipoid or from broken down entangled erythrocytes. Advanced lesions occasionally contained similar dusting with fat in deep parts of organizing emboli.

\section{Discussion}

Three aspects of thrombo-embolic arteriosclerosis will be considered here: are thromboplastininduced arterial lesions solely ascribable to incorporation of fibrin into pulmonary vessels? do they resemble arteriosclerosis? and what evidence is there to support the concept of thrombo-embolic arteriosclerosis in man?

Pulmonary arterial lesions associated with repeated injections of thromboplastin extract cannot be attributed wholly to intimal incorporation of fibrin, because arteritis, segmental granulomatous destruction of arterial walls, and odema are lesions characteristic of experimental anaphylaxis (Klinge, 1930; Vaubel, 1932; Goddard, 1947; and Hawn and Janeway, 1947). However, inflammatory arteritis in rabbit lung is ascribed to anaphylaxis rather than to infected emboli, for the principal reason that similar lesions have not been encountered after injection of autogenous fibrin emboli prepared in vitro by chopping clot fine, using a safety razor blade. As it is not feasible to sterilize either thromboplastin extract or the emboli for fear of denaturing them, though risk of 


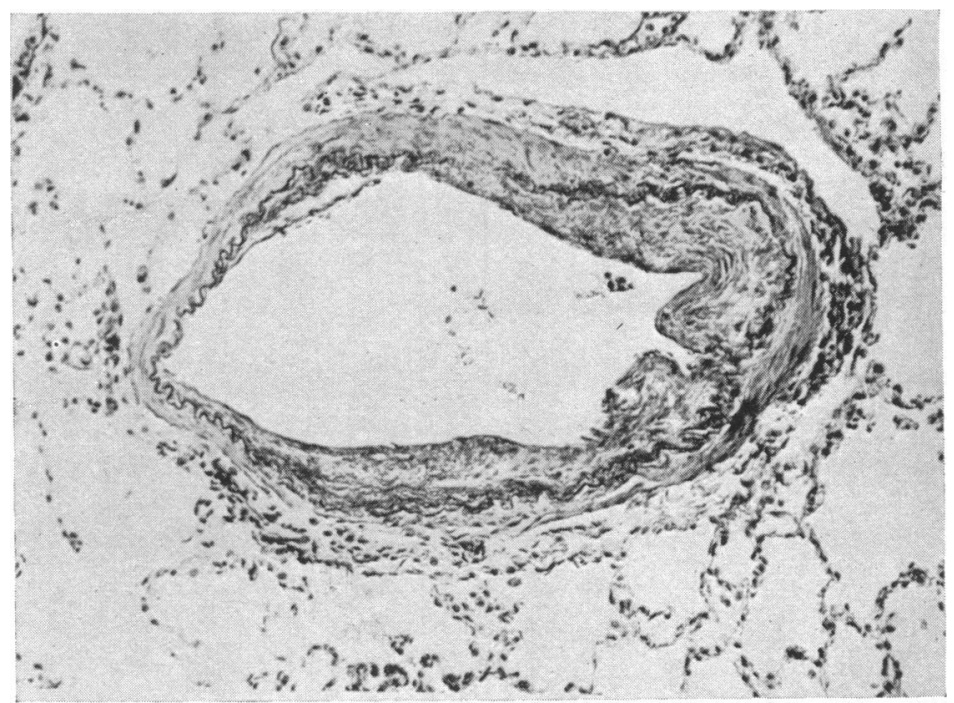

FIG. 5.-Collagenous intimal mass applied eccentrically to arterial wall (Weigert-van Gieson, $\times 140$ ).

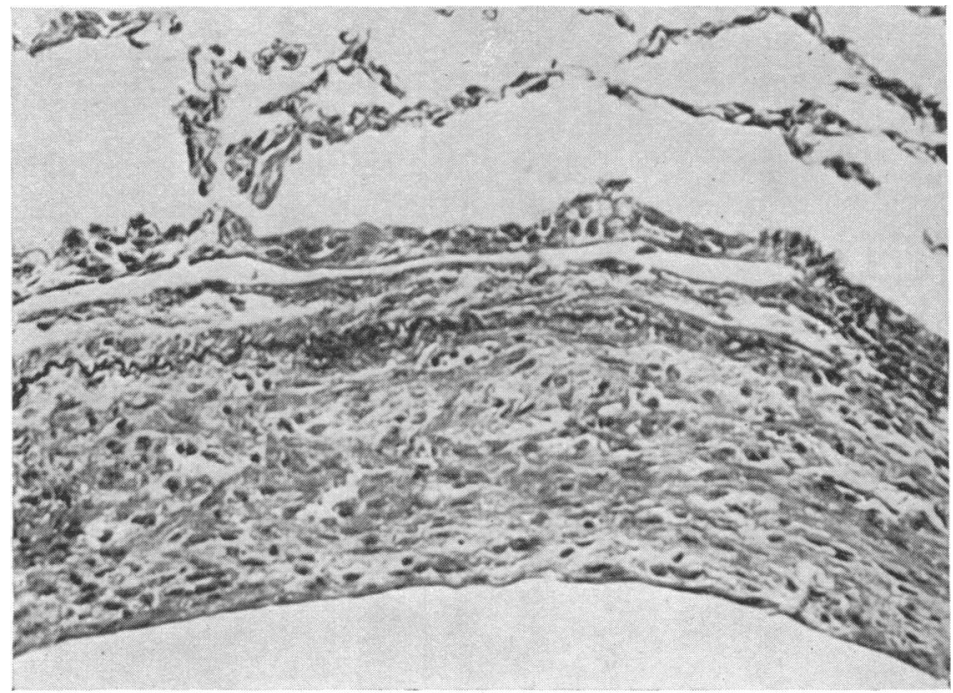

FIG. 6.-Vessel showing loose eccentric connective tissue intimal thickening. Destruction of internal elastica is present (Weigert-van Gieson, $\times 240$ ).

bacterial contamination of either substance is equally great, no inflammatory arteritis has been found when emboli prepared in vitro by the chopping technique were injected. That similar arteritic lesions in mouse lung, on the other hand, are anaphylactic is less certain because behaviour of fibrin emboli prepared in the way described for rabbits, has not been investigated in the lungs of mice (unpublished observations). Thromboplastin extract in repeated doses thus has only restricted usefulness in discovering how fibrin causes arterial disease, for it is impossible to obtain from autogenous sources thromboplastin extract sufficient for experiments like these and so escape errors liable to intrude when foreign protein is injected. 
Nevertheless, though not numerous, other lesions like those of arteriosclerosis were also present (Fig. 5 and 6). Such lesions are often illustrated in case reports of primary pulmonary arteriosclerosis. These experiments have shown, however, that sublethal doses of thromboplastin extract cause fibrin embolism of the lungs and that fibrin emboli become incorporated into arterial intima as connective tissue intimal thickenings sometimes containing new elastic fibres.

The evidence for thrombo-embolic pulmonary arteriosclerosis in man rests upon animal experiments, study of cor pulmonale associated with carcinomatous pulmonary embolism, and upon study of primary pulmonary arteriosclerosis associated with right ventricular hypertrophy.

The lesions of experimental thrombo-embolic arteriosclerosis using fibrin prepared in vitro correspond closely with those described and illustrated in human cases of primary pulmonary arteriosclerosis, a fact also commented upon by Harrison (1948). In experiments still under way in which autogenous fibrin emboli are being repeatedly injected over a long period, rabbits have become severely cyanosed and have died with a morbid anatomical picture in all respects similar to those human cases in which severe pulmonary arteriosclerosis is combined with right ventricular hypertrophy and failure. However, Harrison (1951), who has conducted similar experiments, found that right ventricular hypertrophy gradually subsided after the injection of emboli was stopped. Apart from cyanosis and cardiac failure, which Harrison does not mention in his animals, my incomplete experiments do not as yet suggest an explanation of this discrepancy.

The relationship between pulmonary vascular disease and right ventricular hypertrophy in man is obscure. There are cases of extensive pulmonary vascular disease in which hypertrophy has failed to occur. Conversely, there are cases of right ventricular hypetrophy where the extent of primary pulmonary vascular disease appears to be altogether insufficient (the first case of De Navasquez et al., 1940; the second case of Ulrich, 1932-33; and Brenner, 1935). It is for cases of this type that primary pulmonary hypertension is postulated as the counterpart of primary systemic hypertension with its attendant left ventricular enlargement.

Nevertheless, case reports indicate that not all examples of combined primary pulmonary vascular disease and right ventricular failure need be due to primary pulmonary hypertension. Chronic cor pulmonale associated with widespread organizing thrombosis of small intrapulmonary arteries, due to carcinomatous emboli mainly from gastric neoplasms, illustrates this (Krutzsch, 1920, and Saphir, 1947) - an opinion reinforced by the case of Mantz and Craige (1951) in which right ventricular hypertrophy was associated with organization of small non-malignant embolic clots widely scattered in small intrapulmonary arterial branches. Remarkable also in descriptions of primary pulmonary arteriosclerosis is the large number of cases in which organizing clots in small pulmonary arteries are mentioned. These are uncritically regarded as thromboses secondary to arteriosclerosis, but arteriosclerosis secondary to the presence of blood clot is just as probable (Harrison, 1948 and 1951; Duguid, 1946 and 1948; Heard, 1947; Crawford and Levene, 1952; and Mehrotra, 1953). Cases that could be explained as secondary to incorporation of small clots into pulmonary arterial intima are the second case of Goedel (1930) and the cases described by Eppinger and Wagner (1920). Recurrent or chronic embolism with right ventricular failure due to large clots from veins below diaphragmatic level are now widely recognized (Carroll, 1950). It is conceivable that there is a coagulative blood disorder in which fibrin separates out of systemic venous blood as small clots, instead of the large clots which are easier to find at autopsy.

Finally, even in normal people, circulating blood is not perhaps as fibrin free as is supposed. The comparatively rapid turnover of platelets, prothrombin, and fibrinogen suggests this. Other indirect evidence that blood might be coagulating continuously, derives from the work of Sternberger (1952) who claims to have recovered active thrombin from circulating blood by dissociating it from antithrombin. In disease on the other hand, the wide variety of conditions in which circulating fibrinolysin can be demonstrated also supports the view that intravascular coagulation is far commoner than general opinion at present holds (Biggs and MacFarlane, 1947, and Tagnon et al., 1946).

There are thus substantial reasons to suggest that some cases of primary pulmonary arterio- 
sclerosis and cor pulmonale might result from protracted embolism of pulmonary arteries by minute blood clots. Increasing awareness of this possibility among clinicians and development of methods that detect coagulation in circulating blood should shed further light on this subject.

\section{SUMMARY}

Pulmonary arterial lesions caused in mice and rabbits by intravenous injection of thromboplastin extract by itself are described.

Minute emboli resulting from intravascular coagulation were arrested in the pulmonary arteries. Incorporation of emboli into pulmonary arterial intima ended mainly as connective tissue thickenings. Other lesions, probably anaphylactic, were also encountered.

Evidence is presented that some human cases of severe primary pulmonary arteriosclerosis with right ventricular hypertrophy and failure might be due to protracted embolism by minute fibrin clots.

I am greatly indebted to Professor J. Barnetson for his assistance, to my wife for the technical work. and to Mr. N. Leeuwner for the photographs. The cost of this work was defrayed by the South African Council for Scientific and Industrial Research.

\section{REFERENCES}

Barnard, P. J. (1953). J. Path. Bact., 63, 129.

Belt, T. H. (1939). Lancet, 2, 730.

Biggs, R., and MacFarlane, R. G. (1947). Lancet, 1, 402.

Brenner, O. (1935). Arch. intern. Med., 56, 976.

Carroll, D. (1950). Amer. J. Med., 9, 175.

Crawford, T., and Levene, C. I. (1952). J. Path. Bact., 64, 523.

De Navasquez, S., Forbes, J. R., and Holling, H. G. (1940). Brit. Heart J., 2, 177.

Diguid, J. B. (1946). J. Path. Bact., 58, 207.

- (1948). J. Path. Bact., 60, 57.

Eppinger, E., and Wagner, R. (1920). Wiener Archiv. inn. Med., 1, 83.

Goddard, J. W. (1947). Amer. J. Path., 23, 943.

Goedel, A. (1930). Virchows Archiv. path. Anat. Phys., 277, 507.

Harrison, C. V. (1948). J. Path. Bact., 60, 289. (1951). J. Path. Bact., 63, 195.

Hawn, C. V. Z., and Janeway, C. A. (1947). J. Exp..Med., 85, 571.

Heard, B. E. (1947). J. Path. Bact., 61, 635.

- (1952). J. Path. Bact., 64, 13.

Jürgens, R., and Studer, A. (1948). Helv. Physiol. Pharmacol. Acta, 6, 130.

Klinge, F. (1930). Beitr. path. Anat. alleg. Path., 83, 185.

Krutzsch, G. (1920). Frankfurt. Ztschr. Path., 23, 247.

Mantz, F. A., and Craige, E. (1951). Arch. Path., 52, 91.

Mehrotra, R. M. L. (1953). J. Path. Bact., 65, 307.

McKeown, Florence (1952). Brit. Heart J., 14, 25.

McLetchie, M. G. B. (1952). Amer. J. Path., 28, 413.

Muirhead, E. E., and Montgomery, P. O'B. (1951). Arch. Path., 52, 505.

Page, E. W., Fulton, L. D., and Glendening, Mary B. (1951). Amer. J. Obst. Gynec., $61,1116$.

Ratnoff, O. D., and Conley, L. (1951). Bull. Johns Hopkins Hosp., 88, 414.

Saphir, O. (1947). Amer. J. Path., 23, 245.

Schneider, C. L. (1951). Surg., Gynec. Obst., 92, 27.

Sternberger, L. A. (1952). J. Amer. med. Ass., 150, 1591.

Tagnon, H. J., Levenson, S. M., Davidson, C. S., and Taylor, F. H. L. (1946). Amer. J. med. Sci., 211, 88.

Ulrich, H. L. (1932-33). Ann. intern. Med., 6, 632.

Vaubel, E. (1932). Beitr. path. Anat. alleg. Path, 89, 374. 